ORIGINAL RESEARCH

\title{
Maximum Exercise Responses of Men and Women Mountaineering Trainees on Induction to High Altitude (4350 $\mathrm{m})$ by Trekking
}

\author{
Gopinath Bhaumik, MSc; Deepak Dass, MSc; Himmat Lama, BSc; S. K. S. Chauhan, MSc \\ From the Environmental Physiology Division, Defence Institute of Physiology and Allied Science Defence Research and Development \\ Organization, Timarpur, Delhi, India.
}

\begin{abstract}
Objective.-Maximum aerobic capacity decreases at high altitude. This study was conducted to compare the changes in maximum aerobic capacity in men and women mountaineering trainees on induction to high altitude at $4350 \mathrm{~m}$ by trekking.

Methods.-Eight men and 8 women mountaineering trainees in a mountaineering course were selected for the study. The initial study was conducted at $2100 \mathrm{~m}(586 \mathrm{~mm} \mathrm{Hg})$ and then during 6 to 7 days of sojourn at $4350 \mathrm{~m}(435 \mathrm{~mm} \mathrm{Hg})$. Maximum oxygen consumption $\left(\mathrm{Vo}_{2 \max }\right)$, maximum heart rate $\left(\mathrm{HR}_{\max }\right)$, pulse arterial oxygen saturation $\left(\mathrm{SaO}_{2}\right)$, and maximum ventilation $\left(\mathrm{VE}_{\text {max }}\right)$ were measured.

Results.- $-\mathrm{VO}_{2 \max }, \mathrm{HR}_{\max }$, duration of work (minutes), and $\mathrm{SaO}_{2}$ saturation decreased significantly $(P<.05)$ with increasing altitude in both sexes. Conversely, $\mathrm{VE}_{\max }$ and ventilatory equivalent (VE/ $\left.\mathrm{VO}_{2}\right)$ increased significantly $(P<.05)$. Men showed a relatively higher value of maximum exercise variables (total exercise time, exercise intensity, and $\mathrm{VO}_{2}$ ) than women trainees at both altitude locations. The decrement of $\mathrm{VO}_{2 \max }$ was $13 \%$ in women and $17 \%$ in men $(P<.05)$.

Conclusions.-The results indicate that the decrement of maximum aerobic capacity at $4350 \mathrm{~m}$ was less in women than in men under similar modes of ascent.
\end{abstract}

Key words: high altitude, maximal exercise, aerobic capacity

\section{Introduction}

Physiologically, an elevation of $2500 \mathrm{~m}$ (8250 feet) above sea level is considered high altitude, because at this height arterial oxygen saturation $\left(\mathrm{SaO}_{2}\right)$ falls in most people. ${ }^{1}$ In addition to hypoxia, severe cold, low humidity, and solar radiation pose serious problems in the human body. Exposure of sea level residents to high altitude evokes a series of physiological stress responses associated with hypoxemia, and these are lessened by the process of acclimatization with continued exposure. Maximal aerobic power $\left(\mathrm{VO}_{2 \max }\right)$ is widely used as a performance index and generally accepted as the single best measure of the functional limit of the combined respiratory and circulatory systems to deliver oxygen to active muscles and the ability of the muscles to use ox-

Corresponding author: Gopinath Bhaumik, MSc, Environmental Physiology Division, Defence Institute of Physiology and Allied Science Defence Research and Development Organization, Timarpur, Delhi-110054, India (e-mail: g_bhaumik1@yahoo.co.in). ygen. $^{2}$ Under the hypoxic conditions associated with high altitude there is a decrease in $\mathrm{VO}_{2 \text { max }} \cdot{ }^{3}$

Exercise responses of men at varying altitudes have been extensively studied, but not much attention has been given to investigating the exercise response in women. The comparison between men and women at high altitude at rest has indicated some differences in physiological parameters. Cudkowicz et $\mathrm{al}^{4}$ showed an increase in the forced expiratory volume in 1 second of female sojourners at $5200 \mathrm{~m}$, whereas in males it remained unchanged. Women living at low altitude have greater ventilation relative to carbon dioxide production, that is, lower end tidal partial pressure carbon dioxide, compared with men. ${ }^{4,5}$ This greater alveolar ventilation in women compared with men at sea level suggests that women may be predisposed to a more rapid ventilatory acclimatization response at high altitude. A few studies on women's responses to maximal exercise under hypobaric hypoxic conditions reported varying results. ${ }^{6-8}$ Our earlier study on submaximal work performance in 
Table. Physiological responses to maximal exercise in men and women at different altitudes*

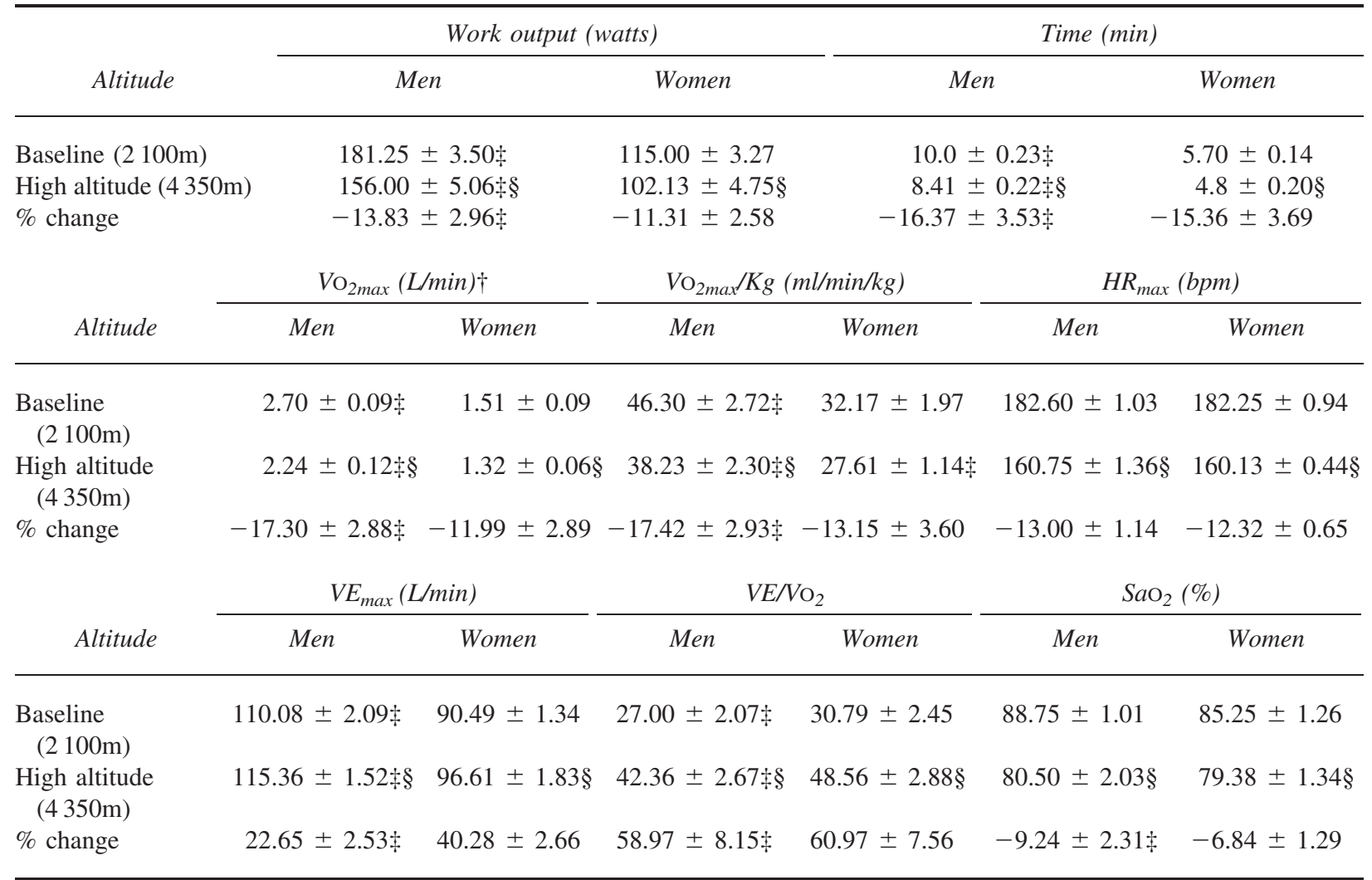

*Values are mean \pm SEM; each group had 8 individuals; significance $=P<.05$.

$\dagger \mathrm{VO}_{2 \text { max }}$ indicates maximum oxygen consumption; $\mathrm{HR}_{\max }$, maximum heart rate; $\mathrm{VE}_{\max }$, maximum ventilation; $\mathrm{SaO}_{2}$, arterial oxygen saturation; $\mathrm{VE} / \mathrm{VO}_{2}$, ventilatory equivalent for oxygen; min, minutes; bpm, beats/minute.

$\ddagger$ Indicates men vs women.

§Indicates baseline $2100 \mathrm{~m}$ vs high altitude $4350 \mathrm{~m}$.

women mountaineers at $2100 \mathrm{~m}$ and $4350 \mathrm{~m}$ altitudes indicated that native women of moderate altitudes were more fit than their sea level counterparts and that induction to high altitude by trekking under progressive hypoxia coupled with rigorous mountaineering activity provides better acclimatization and improved physical work performance. ${ }^{9}$ However, the effect of altitude on maximal exercise responses in men and women mountaineering training under similar regimens of ascent by trekking has not been studied. The present study sought to investigate the rate of changes of maximum exercise responses in men and women at $4350 \mathrm{~m}$ altitude while undergoing mountaineering training under similar regimens.

\section{Materials and methods}

Eight men and 8 women trainees were randomly selected for this study from a total of 50 trainees who came to Himalayan Mountaineering Institute (HMI), Darjeeling
(2100 m), India, for a basic mountaineering course. All of them were medically fit. None of the participants had been to high altitudes within the previous 3 months. The participants gave their informed consent and were aware of their rights to withdraw from the experiments at any time. The Ethics Committee of the institute approved the experimental protocol.

Initial pretraining measurements of maximum exercise test were carried out in the medical investigation room at HMI (Darjeeling) with a room temperature of $16^{\circ} \mathrm{C}$ to $20^{\circ} \mathrm{C}$. The same investigations were repeated on induction to high altitude at Chaurikhang, the base camp of HMI $(4350 \mathrm{~m})$, within a makeshift laboratory inside the Silver Hut, where the room temperature was maintained between $17^{\circ} \mathrm{C}$ and $20^{\circ} \mathrm{C}$, with the help of bukharies (gas or kerosene heaters). This Silver Hut was used by a scientific and mountaineering expedition team in 1960 and 1961 led by Sir Edmound Hillary on Ama Dablam glacier at an altitude of $5800 \mathrm{~m}$, about $15 \mathrm{~km}$ south of Mount Everest. Presently, it is under the man- 
agement of HMI (Darjeeling) at Chaurikhang in the eastern Himalayas, the base camp of HMI. The study was conducted in 2 phases: 1) a baseline study was carried out during the first 3 days of stay at HMI (2100 m, barometric pressure $586 \mathrm{~mm} \mathrm{Hg}$ ), and 2) a high altitude study was conducted on days 6 and 7 at $4350 \mathrm{~m}$ (barometric pressure $435 \mathrm{~mm} \mathrm{Hg}$ ) in the Silver Hut. All the tests were conducted by the same group of observers with the same set of equipment in both sites.

At HMI (Darjeeling), the trainees underwent a rigorous training schedule of mountaineering activities [1 week] from early morning until late evening with intermittent breaks. After a week's training at Darjeeling, they set out on their journey to the base camp (4350 m elevation). The trainees were transported $(160 \mathrm{~km})$ by bus (day 8) from Darjeeling to Yoksom (2200 m elevation). On the next morning (day 9), all the trainees trekked for about $15 \mathrm{~km}$ and reached Bhakim (2750 m), where they stayed for the next day (day 10). On day 11 , the participants walked to Zamlingaon $(3600 \mathrm{~m}$ elevation) after crossing over a height of $4500 \mathrm{~m}$, covering a distance of $12 \mathrm{~km}$, and halted there for the next day (day 12) for acclimatization. On day 13, the trainees trekked about $14 \mathrm{~km}$ and reached the base camp of HMI at Chowrikhang $(4350 \mathrm{~m})$. The trainees trekked about 2 to $3 \mathrm{~km} / \mathrm{h}$ for 5 to 6 hours each day at increasing altitude under progressive hypoxia while carrying a load of approximately $15 \mathrm{~kg}$.

During days 14 to 23 (10 days), participants stayed at $4350 \mathrm{~m}$ in a hut made of metal sheets and fitted with bunks. They used appropriate winter clothing. They undertook intense mountaineering training that involved glacier marching, ice cutting, peak assault, back packing, repelling, and rock climbing and were engaged in snowbound field areas at higher elevations in the forenoon and nearby camp areas in the afternoon. On the penultimate day of training, they climbed a peak of about $5550 \mathrm{~m}$.

The maximum and minimum ambient temperatures at the base camp during the period of study were $+10^{\circ} \mathrm{C}$ and $-7^{\circ} \mathrm{C}$, respectively. Sunshine and partial cloudiness during the day with occasional snowfall and high-velocity wind are the characteristic features of the area. At high altitude, none of the participants exhibited any symptoms of discomfort or acute altitude sickness, and they were not taking any medication. A clinical assessment was made by a trained physician from HMI during the morning assembly every day. The trainees were free to report their ailments/discomfort and/or injuries without any fear. All of them ate well, slept well, and worked as demanded in the course syllabus. After 10 days of sojourn at $4350 \mathrm{~m}$, they returned to HMI (2100 m), which involved 2 days of trekking (days 24 and 25) and a motor journey of 1 day (day 26).

Participants were allowed to sit comfortably for 10 minutes before the start of the experiment in the laboratory at both $2100 \mathrm{~m}$ and $4350 \mathrm{~m}$. Exercise tests were performed on a calibrated cycle ergometer with a pedal rate of $60 \mathrm{rpm}$. Participants were lightly dressed and wore appropriate shoes. The room temperature was between $18^{\circ} \mathrm{C}$ and $20^{\circ} \mathrm{C}$, and relative humidity was $50 \%$ to $60 \%$.

The exercise protocol was a modification of that described by Wasserman et al. ${ }^{10}$ After a resting period of 3 minutes on the bicycle, the participants exercised at zero workload for 3 minutes until the heart rate and respiratory values reached a steady state. At the end of the zero-load pedaling period, the work intensity was increased, starting at 30 watts followed by an incremental increase of 15 watts every minute until volitional fatigue occurred. When the heart rate was about 170 beats $\cdot \min ^{-1}$, participants were encouraged to continue the test until exhaustion. The volunteer breathed through a low-resistance respiratory valve and breathing circuit connected to a computer-controlled, breath-by-breath metabolic measurement system (Benchmark Exercise Test System and Nutrition monitor, PK Morgan, Kent, $\mathrm{UK}$ ). Minute ventilation (VE) and oxygen consumption $\left(\mathrm{VO}_{2}\right)$ were measured breath by breath with the metabolic measurement system. Heart rate by electrocardiogram (lead-II) was monitored on a cardiac monitor and connected to an online computer. Arterial oxygen saturation was measured by a portable finger pulse oximeter (N-20 SA, Nellcor, Pleasanton, CA) just at the end of the exercise.

Statistical analysis of the data was performed by 2-way classification of an analysis of variance technique using the Newman-Keuls multiple range test to compare the same group at different situations. An unpaired $t$ test was used for the comparison of men and women for each situation. A 5\% level of significance was considered the critical level.

\section{Results}

The mean and SEM values of age and height were 20.6 \pm 1.02 years and $154.0 \pm 1.32 \mathrm{~cm}$ for females and $22.38 \pm 0.32$ years and $154.50 \pm 0.89 \mathrm{~cm}$ for males, respectively. Body surface area was similar in both the groups. The body weights were $47.25 \pm 1.70 \mathrm{~kg}$ for females and $59.1 \pm 2.79 \mathrm{~kg}$ for males. Mean $\pm \mathrm{SEM}$ values of cardiorespiratory variables during maximal exercise at $2100 \mathrm{~m}$ and at $4350 \mathrm{~m}$ in men and women and their comparisons are presented in the table. Total work time and maximal power output were less in women 
than men at both altitudes. At $2100 \mathrm{~m}$ men showed maximum work output of 181 watts compared with women, who reached only 115 watts. Total working time was 10.1 minutes in men and 5.7 minutes in women. On ascent to high altitude $(4350 \mathrm{~m})$, both men and women showed significant decrement of maximum work capacity, as well as working time. At $4350 \mathrm{~m}$ altitude, maximum power output for men was 156 watts and for women 102 watts, and total work times were 8.4 and 4.8 minutes, respectively.

Maximum oxygen consumption $\left(\mathrm{VO}_{2 \max }\right)$ values showed significant decrements in both men $(17 \%)$ and women $(13 \%)$. Maximum heart rate $\left(\mathrm{HR}_{\max }\right)$ showed significant decrements at $4350 \mathrm{~m}$ altitude in both sexes. Significant increases in maximal ventilation $\left(\mathrm{VE}_{\max }\right)$ were observed in both men and women at $4350 \mathrm{~m}$ but not at $2100 \mathrm{~m}$. The ventilatory equivalent for oxygen $\left(\mathrm{VE} / \mathrm{Vo}_{2}\right)$ was also increased significantly in both groups, but the rate of increment was higher in women than in men. Exercise $\mathrm{SaO}_{2}$ value further decreased at $4350 \mathrm{~m}$ altitude in both sexes from their base line exercise value at $2100 \mathrm{~m}$.

\section{Discussion}

Reports of gender variance on hypoxic tolerance ${ }^{11-13}$ and maximum exercise responses at high altitude are limited. A recent review by Jean et $\mathrm{al}^{14}$ discussed women (both nonpregnant and pregnant) going to high altitudes for brief periods. The present study evaluated the decrement of maximum exercise responses of men and women at $4350 \mathrm{~m}$ altitude while undergoing mountaineering training that was similar to ascending by trekking. We found a significant reduction in $\mathrm{VO}_{2 \max }$ in men and women at $4350 \mathrm{~m}$ altitude, but the rate of decrement was less in women $(13 \%)$ than in men $(17 \%)$. However, the decrement of $\mathrm{VO}_{2 \max }$ at $4350 \mathrm{~m}$ was less compared with the trends reported in other studies done at similar altitudes. ${ }^{6,15-18}$ Few studies have focused on $\mathrm{VO}_{2 \max }$ in women during altitude exposure or during hypoxic gas mixture breathing. ${ }^{6,15,16,19,20,21}$ Only 5 studies have made direct gender comparisons ${ }^{6,16,20,22,23}$ on maximum exercise responses. Direct observations in a study of females indicated a $26.7 \%$ decrement of $\mathrm{Vo}_{2 \max }$ at 4100 m. ${ }^{15}$ In another study, a $24 \%$ reduction of $\mathrm{VO}_{2 \max }$ in females compared with a $29.5 \%$ reduction in males at $4500 \mathrm{~m}$ altitude was reported. ${ }^{6}$ Elliott and Atterbom ${ }^{16}$ observed a similar decrement $(18 \%)$ of $\mathrm{VO}_{2 \max }$ in both sexes at $3962 \mathrm{~m}$ altitude.

In this study the minimal effect we found of altitude on maximal work performance in men and women mountaineering trainees may be due to their gradual ascent by trekking, as well as their participation in such mountaineering activities as heavy lifting, rock climbing, peak assault, and glacier marching. The participants of the present study appeared properly acclimatized on the day they reached $4350 \mathrm{~m}$ altitude. None of them showed any indications of acute altitude sickness, and they all ate and slept well during their stay at $4350 \mathrm{~m}$, indicating a proper level of acclimatization. The limitation of our study is that we could not measure spirometry and hemoglobin levels due to unfavorable circumstances. A spirometry test given just before exercise would have enabled a better comparison in men and women participants with regard to evaluating ventilatory responses. The measurement of hemoglobin levels could have given a more distinct difference in aerobic capacity, because hemoglobin levels are $11 \%$ to $14 \%$ lower in women than men, ${ }^{24}$ which further limits oxygen delivery and uptake capacity.

With respect to ventilatory response, the increase in $\mathrm{VE} / \mathrm{VO}_{2}$ at high altitude may be due to effect of the peripheral chemoreceptors on VE during hypoxia. This improves blood oxygenation and is also known to be the most effective mechanism of altitude acclimatization during the initial phase. Both Drinkwater et al ${ }^{15}$ and Paterson et $\mathrm{al}^{6}$ observed significant gender differences in $\mathrm{VE} / \mathrm{VO}_{2}$ responses (higher in female), whereas Elliott and Atterbom ${ }^{16}$ showed no gender differences. In our study, we found relatively higher $\mathrm{VE} / \mathrm{VO}_{2}$ values in women than in men at both the altitude locations. All the participants were inducted to high altitude by trekking with mountaineering activities. Earlier studies on men and women showed greater alveolar ventilation in women than men during initial days of exposure at high altitude. $^{4,25,26}$ However, Muza et $\mathrm{al}^{27}$ reported that female lowlanders rapidly ascending to $4350 \mathrm{~m}$ altitude in either the follicular or the luteal phase of the menstrual cycle have a similar level of alveolar ventilation, and the time course for ventilatory acclimatization is nearly identical to that reported in male lowlanders.

With acute altitude exposure, there is a reduction in arterial oxygen content. ${ }^{28}$ However, with sustained exposure for a few days at high altitude, arterial oxygen content is restored to near sea level values due to hemoconcentration and an increase in $\mathrm{SaO}_{2}$. As a consequence of hemoconcentration, stroke volume and cardiac output are reduced. During submaximal levels of exercise, the restored oxygen content compensates for the reduced cardiac output such that oxygen transport to the working muscles is maintained. During the maximal level of exercise, however, the restored arterial oxygen content cannot compensate for the altitude-induced decline in maximal cardiac output, and therefore $\mathrm{VO}_{2 \max }$ does not improve. ${ }^{3}$ A recent study on $\mathrm{HR}_{\max }$ and $\mathrm{SaO}_{2}$ on the decrement of $\mathrm{VO}_{2 \max }$ in moderate acute hypoxia in 
trained and untrained men showed that the reduction in $\mathrm{SaO}_{2}$ may be the primary factor explaining the drop of $\mathrm{VO}_{2 \max } \cdot{ }^{29}$ In our study, we found a significant decrement of $\mathrm{HR}_{\max }$ and $\mathrm{SaO}_{2}$ during maximum exercise at 4350 $\mathrm{m}$ altitude in both men and women mountaineering trainees.

In conclusion, our results indicated that there was a significant decrement of $\mathrm{VO}_{2 \max }$ in both sexes on exposure to hypobaric hypoxia at $4350 \mathrm{~m}$ under similar regimens of mountaineering training, but the rate of decrement of $\mathrm{VO}_{2 \max }$ was less in women than in men.

\section{Acknowledgments}

We are grateful to the Principal Himalayan Mountaineering Institute, Col Vijay Singh, Medical Officer HMI, Major A. Chakravorty and staff of HMI, Darjeeling, for providing logistic support for the study. Warm thanks are due to all the trainees of the Basic Mountaineering course who volunteered as participants for their wholehearted cooperation. We thank the Field Director, as well as all the instructors of HMI for their help during the study. Acknowledgment is due to Dr S. S. Verma, Sc 'F', Dr Y. K. Sharma, Sc 'D,' and Mrs Shikha Anand for statistical analysis of the data. We are thankful to Dr U.S. Ray, Sc 'E,' Divisional Head, Environmental Physiology Division, and Dr G. Ilavazhagan, Sc 'G,' Director of Defence Institute of Physiology and Allied Sciences.

\section{References}

1. Moore LG. Comparative human ventilatory adaptation to high altitude. Respir Physiol. 2000;121:257-276.

2. Astrand PO, Rodahl K. Textbook of Work Physiology: Physiological Bases of Exercise. 3rd ed. New York: Mcgraw-Hill Book Co; 1986.

3. Calbet JAL, Bousel R, Radegran G, et al. Why is $\mathrm{VO}_{2 \max }$ after altitude acclimatization still reduced despite normalization of arterial $\mathrm{O}_{2}$ content? Am J Physiol. 2003; 284:R304-R316.

4. Cudkowicz L, Spielvogel H, Zubeieta G. Respiratory studies in women at high altitude $(3600 / 5200 / 17,200 \mathrm{ft})$. Respiration. 1972;29:393-426.

5. Aitken ML, Franklin J L, Pierson DJ, Schoene RB. Influence of body size and gender on control of ventilation. $J$ Appl Physiol. 1986;60:1894-1899.

6. Patterson DJ, Pinnington H, Pearce, AR. Morton AL. Maximal exercise cardiorespiratory responses of men and women during acute exposure to hypoxia. Aviat Space Environ Med. 1987;58:243-247.

7. Drinkwater BL, Kramar PO, Bedi JF, Folinsbee LJ. Women at altitude: cardiovascular response to hypoxia. Aviat Space Environ Med. 1982;53:472-477.

8. Hartley LH, Vogel JA, Cruz JC. Reduction of maximal exercise heart rate at altitude and its reversal with atropine. J Appl Physiol. 1974;36:362-365.

9. Purkayastha SS, Bhaumik G, Sharma RP, Arora BS, Selvamurthy W. Effects of mountaineering training at high altitude $(4350 \mathrm{~m})$ on physical work performance of women. Aviat Space Environ Med. 2000;71:685-691.

10. Wasserman K, Whipp BJ, Koyal SN, et al. Anaerobic threshold and respiratory gas exchange during exercise. $J$ Applied Physiol. 1973;35:236-243.

11. Bhaumik G, Sharma RP, Dass D, et al. Hypoxic ventilatory response change of men and women 6 to 7 days after climbing from $2100 \mathrm{~m}$ to $4350 \mathrm{~m}$ altitude and after descent. High Alt Med Biol. 2003;4:341-348.

12. Bhaumik G, Purkayastha SS, Sharma RP, et al. Chemoreceptor sensitivity in women mountaineering trainees of different altitudes inducted by trekking to $4350 \mathrm{~m}$. Defence Sci J. 2005;55:427-435.

13. Choi JM, Jung CK, Min TH, et al. Difference of hypoxia tolerance with reference to sex. Korean J Aerosp Environ Med. 2003;13:131-335.

14. Jean D, Leal C, Kriemler S, Meijer H, Moore LG. Medical recommendations for women going to altitude: a medical commission UIAA consensus paper. High Alt Med Biol. 2005;6:22-31.

15. Drinkwater BL, Folinsbee LJ, Bedi JF, et al. Response of women mountaineers to maximal exercise during hypoxia. Aviat Space Environ Med. 1979;50:657-662.

16. Elliot PR, Atterbom HA. Comparison of exercise responses of males and females during acute exposure to hypobaria. Aviat Space Environ Med. 1978;49:415-418.

17. Buskrirk ER, Kollias J, Akers RF, Prokop EK, Reategui EP. Maximal performance at altitude and on return from altitude in conditioned runners. J Appl Physiol. 1967;23: 259-266.

18. Gleser MR, Vogel JA. Effects of acute alteration of $\mathrm{VO}_{2 \max }$ on endurance capacity of men. J Appl Physiol. 1973;34:443-447.

19. Beidleman BA, Rock PB, Muza SR, et al. Menstrual cycle phase does not affect work performance at sea level and 4300 m [abstract]. In: Sutton JR, Houston CS, Coates G, eds. Hypoxia and the Brain, $9^{\text {th }}$ International Hypoxia Symposium. Lake Louise, Alberta, Canada: Queen City Printers; 1995.

20. Levitan BM, Bungo MW. Measurement of cardiopulmonary performance during acute exposure to a $2440 \mathrm{~m}$ equivalent atmosphere. Aviat Space Environ Med. 1982; 53:639-642.

21. Wagner JA, Miles DS, Horvath SM, Reyburn JA. Maximal work capacity of women during acute hypoxia. $J$ Appl Physiol. 1979;47:1223-1227.

22. Robergs RA, Quintana R, Parker DL, Frankel CC. Multiple variables explain the variability in the decrement in $\mathrm{VO}_{2 \max }$ during acute hypobaric hypoxia. Med Sci Sports Exerc. 1998;30:869-879.

23. Shephard RJ, Bouhlel E, Vandewalle H, Monod H. Peak oxygen uptake and hypoxia. Int J Sports Med. 1988;9: 279-283. 
24. Greeves J. Physical training of women in the military. $J$ Defence Sci. 2001;6:228-238.

25. Loeppky JA, Scotto P, Charlton GC, et al. Ventilation is greater in women than men, but the increase during acute altitude hypoxia is the same. Respir Physiol. 2001;125:225-237.

26. White DP, Douglas NJ, Pickett CK, Weil JV, Zwillich CW. Sexual influence on the control of breathing. J Appl Physiol. 1983;54:874-879.

27. Muza SR, Rock PB, Fulco CS, et al. Women at altitude: ventilatory acclimatization at $4350 \mathrm{~m}$. J Appl Physiol. 2001;91:1791-1799.

28. Fulco CS, Rock PB, Cymerman A. Improving athletic performance: is altitude residence or altitude training helpful? Aviat Space Environ Med. 2000;71:162-171.

29. Mollard P, Woorons X, Letournel M, et al. Role of maximal heart rate and arterial $\mathrm{O}_{2}$ saturation on the decrement of $\mathrm{VO}_{2 \max }$ in moderate acute hypoxia in trained and untrained men. Int J Sports Med. 2007;28:186-192. 